\title{
Pharmacokinetics of Teriparatide (rhPTH[1-34]) and Calcium Pharmacodynamics in Postmenopausal Women with Osteoporosis
}

\author{
Julie Satterwhite $\cdot$ Michael Heathman • \\ Paul D. Miller · Fernando Marín · Emmett V. Glass • \\ Harald Dobnig
}

Received: 4 March 2010/Accepted: 13 August 2010/Published online: 16 October 2010

(C) The Author(s) 2010. This article is published with open access at Springerlink.com

\begin{abstract}
Teriparatide (rhPTH[1-34]) affects calcium metabolism in a pattern consistent with the known actions of endogenous parathyroid hormone (PTH). This report describes the pharmacokinetics and resulting serum calcium response to teriparatide in postmenopausal women with osteoporosis. Pharmacokinetic samples for this analysis were obtained from 360 women who participated in
\end{abstract}

J. Satterwhite, M. Heathman, and F. Marín are full-time employees of Eli Lilly and Company. E. Glass was an employee of Eli Lilly and Company during the preparation of this manuscript and is now an employee of Amgen. H. Dobnig received lecture fees from Eli Lilly and Company, Roche, Novartis, Nycomed, and Servier. P. Miller has received scientific grants from Procter \& Gamble, Sanofi Aventis, Roche, Eli Lilly and Company, Merck \& Co., Novartis, and Amgen. P. Miller is on the speaker/advisory boards and consultant for Procter \& Gamble, Sanofi Aventis, Merck \& Co., Eli Lilly and Company, Amgen, NPS Pharmaceuticals, Novartis, Roche, and GlaxoSmithKline.

J. Satterwhite $\cdot$ M. Heathman · E. V. Glass

Lilly Research Laboratories, Eli Lilly and Company,

Indianapolis, IN, USA

P. D. Miller

University of Colorado Health Sciences Center,

Denver, CO, USA

P. D. Miller

Colorado Center for Bone Research,

Lakewood, CO, USA

F. Marín

Lilly Research Centre, Eli Lilly and Company,

Windlesham, UK

H. Dobnig $(\bowtie)$

Division of Endocrinology and Nuclear Medicine,

Department of Internal Medicine, Medical University of Graz,

Auenbruggerplatz 15, 8036 Graz, Austria

e-mail: harald.dobnig@meduni-graz.at the Fracture Prevention Trial. Postmenopausal women with osteoporosis received daily subcutaneous injections of either teriparatide $20 \mu \mathrm{g}(4.86 \mu \mathrm{mol})$ or placebo, median 21 months' treatment. Serum teriparatide and calcium concentrations were measured throughout the study. An indirect-response model was developed to describe the pharmacokinetic-pharmacodynamic relationship between teriparatide concentrations and serum calcium response. The pharmacokinetics of teriparatide were characterized by rapid absorption (maximum concentration achieved within $30 \mathrm{~min}$ ) and rapid elimination (half-life of $1 \mathrm{~h}$ ), resulting in a total duration of exposure to the peptide of approximately $4 \mathrm{~h}$. Teriparatide transiently increased serum calcium, with the maximum effect observed at approximately $4.25 \mathrm{~h}$ (median increase $0.4 \mathrm{mg} / \mathrm{dl}[0.1 \mathrm{mmol} / \mathrm{l}]$ ). Calcium concentrations returned to predose levels by $16-24 \mathrm{~h}$ after each dose. Persistent hypercalcemia was not observed; one teriparatide $20 \mu \mathrm{g}$-treated patient had a predose serum calcium value above the normal range but $<11.0 \mathrm{mg} / \mathrm{dl}$ $(2.75 \mathrm{mmol} / \mathrm{l})$. Following once-daily subcutaneous administration, teriparatide produces a modest but transient increase in serum calcium, consistent with the known effects of endogenous PTH on mineral metabolism. The excursion in serum calcium is brief, due to the short length of time that teriparatide concentrations are elevated.

Keywords Anabolic agent - Osteoporosis therapy · Peptide hormone - Parathyroid hormone - Teriparatide pharmacokinetics $\cdot$ Calcium pharmacodynamics

The extracellular calcium concentration is of utmost importance for maintenance of both intracellular and extracellular processes playing a critical role in the regulation of a variety of physiological functions. In response to 
slight decrements in extracellular calcium levels, there is a rapid (within seconds) increase in the rate of parathyroid hormone $(\mathrm{PTH})$ release into the systemic circulation $[1,2]$. The most immediate effect of PTH is on the renal tubule, where it stimulates conservation of calcium. This effect is almost instantaneous and is the primary way PTH regulates serum calcium minute by minute. If elevated for $1-2 \mathrm{~h}$, PTH stimulates translocation of calcium from an extracellular compartment located between bone lining cells and the bone surface into the circulation. Finally, if elevated for several hours, PTH promotes intestinal absorption of calcium by stimulating the conversion of $25-\mathrm{OH}$ vitamin $\mathrm{D}$ to the highly active 1,25-dihydroxyvitamin D [3]. PTH regulation by calcium, coupled with the rapid secretion and rapid clearance (half-life $<2 \mathrm{~min}$ ) of the endogenous hormone, assures that PTH can adjust to sudden changes in plasma calcium flux [4].

Teriparatide, recombinant human parathyroid hormone (rhPTH[1-34]), is a skeletal anabolic agent that, when injected subcutaneously once daily, increases bone mass and reduces the risk of osteoporotic fracture [5-8]. Calcium metabolism is affected in a pattern consistent with the known actions of endogenous PTH. Given the role of PTH in the regulation of extracellular calcium over both shortand long-term periods, it is important to understand the time course of the calcemic response to exogenously administered teriparatide as well. The purpose of this article is to describe the pharmacokinetics (PK) and resulting serum calcium pharmacodynamic (PD) response following subcutaneous injection of $20 \mu \mathrm{g}(4.86 \mu \mathrm{mol})$ of teriparatide in postmenopausal women with osteoporosis participating in the Fracture Prevention Trial [6].

\section{Materials and Methods}

\section{Study Design and Participants}

Full details on the Fracture Prevention Trial have been published elsewhere [6]. Postmenopausal women with osteoporosis and prevalent fractures were randomized to receive once-daily subcutaneous injections of teriparatide $20 \mu \mathrm{g}(n=541)$, teriparatide $40 \mu \mathrm{g}(n=552)$, or placebo $(n=544)$ plus daily calcium $(1,000 \mathrm{mg})$ and vitamin $\mathrm{D}$ (400-1,200 IU) supplements. This report includes results from the marketed $20-\mu \mathrm{g} /$ day dose of teriparatide. Study exclusion criteria included the following: diagnosis with any disease known to affect bone or calcium metabolism, urolithiasis within 2 years, serum creatinine level $>2 \mathrm{mg} / \mathrm{dl}$, alcohol or drug abuse, and medication use known to alter bone metabolism within the previous 2-24 months depending on the drug. Patients who were treated with oral bisphosphonates within 3 months of randomization or for more than 60 days in the 24 months prior to randomization or who were treated with intravenous bisphosphonate within 24 months prior to randomization were excluded.

All study sites obtained institutional review board approval. Written informed consent was given by each participant prior to her inclusion in the study. Study methods and procedures were conducted in accordance with the ethical standards of the 1964 Declaration of Helsinki.

\section{Teriparatide and Calcium Measurements}

Serum teriparatide concentrations were measured in a subset of 360 patients at months 1, 3, 6, 12, and 18. One blood sample was collected per patient at each study visit within prespecified sampling windows of $0-30 \mathrm{~min}$, 30 min $-1 \mathrm{~h}, 1-2 \mathrm{~h}, 2-3 \mathrm{~h}$, and $3-4 \mathrm{~h}$ postdose. The exact postdose collection times were documented. The blood sampling scheme was based on a sparse sampling strategy such that a complete PK profile was not obtained from each patient but, rather, a few samples were drawn from many patients and the data combined to characterize the PK profile for the population [9]. The serum was separated from whole blood by centrifugation and stored at $-70^{\circ} \mathrm{C}$ until assayed. Teriparatide was measured by a validated two-site immunoradiometric assay (Phoenix International, Montreal, Canada). Two different antibodies to the 1-34 region of PTH were supplied by Immutopics (San Clemente, CA). One antibody was immobilized on a plastic bead and used to capture teriparatide. The second antibody was labeled with ${ }^{125} \mathrm{I}$ and used to detect the bound teriparatide.

The specificity of the assay was determined by using PTH(1-34) and smaller fragments. The assay could detect (1-31) but not (1-27) on the C terminus; it could also detect (2-34) and (3-34) but not (4-34) on the $\mathrm{N}$ terminus. The percent cross-reactivity of PTH(1-84), relative to the PTH(1-34) standards, was $67 \%$ on a molar basis. However, results from phase 1 and phase 3 studies demonstrated that endogenous PTH secretion was dramatically suppressed following teriparatide injection (data on file); thus, interference by endogenous $\mathrm{PTH}(1-84)$ in the quantification of PTH(1-34) was negligible. Serial blood samples collected from a phase 1 study demonstrated that the decline in PTH(1-84) concentrations was immediate, reaching a nadir approximately $2 \mathrm{~h}$ postdose and remaining suppressed for at least $6 \mathrm{~h}$ in most subjects. In the phase 3 study that is the focus of this report, $\mathrm{PTH}(1-84)$ was measured at screening and 12 months after initiation of teriparatide therapy. During screening visits, prior to teriparatide treatment, mean PTH(1-84) was $35 \mathrm{pg} / \mathrm{ml}$; there were no samples below the limit of quantification for the $\mathrm{PTH}(1-84)$ assay, i.e., $<16.6 \mathrm{pg} / \mathrm{ml}$. Following 12 months of teriparatide treatment, $91 \%$ of the samples were below quantifiable 
limits. The high number of nonquantifiable samples illustrates the suppression of endogenous PTH secretion during teriparatide therapy, suggesting minimal interference in the detection of PTH(1-34).

The PTH(1-34) assay was validated to accurately and reproducibly quantify exogenously administered $\mathrm{PTH}(1-34)$; accuracy and precision were both $\pm 20 \%$. A standard curve of $9.8-20,000 \mathrm{pg} / \mathrm{ml}$ was used with the quantification range of $50-2,000 \mathrm{pg} / \mathrm{ml}$ determined in the assay validation experiments.

Blood samples for serum calcium were collected in all patients at baseline (i.e., prerandomization) and 4-6 $\mathrm{h}$ after injection at 1, 3, 6, 12, 18, and 24 months of treatment. Additionally, routine clinical chemistry laboratory testing, which included serum calcium, was performed at baseline and at 1, 6, 12, and 24 months of treatment. The clinical chemistry labs were collected at random times, and the exact postdose collection time was documented. If the calcium concentration was $>10.6 \mathrm{mg} / \mathrm{dl}(2.647 \mathrm{mmol} / \mathrm{l})$, the test was normally repeated within a couple of weeks. If the retest value was also elevated, the calcium supplement dose was reduced or discontinued or the dose of the injectable study material was reduced by half and the serum calcium laboratory test repeated. If still elevated, the patient was discontinued from the trial. Adverse events were collected throughout the trial.

All clinical chemistry labs from an individual patient were performed at one of three laboratories that used identical, cross-calibrated methods of measurement. Serum albumin was normal in the study population, and adjusting serum calcium concentrations for albumin appeared only to increase the variability of the measure without having a significant effect on the mean values; therefore, the unadjusted total serum calcium is presented.

\section{PK Model}

A population PK model was first developed to characterize the concentration-time profile following subcutaneous injection of teriparatide $[9,10]$. Both one-compartment and two-compartment open linear models were considered for the PK model. Absorption was assumed to follow a firstorder process, and elimination was assumed to occur from the central compartment in the two-compartment model. These models were parameterized in terms of absorption rate constant $\left(K_{\mathrm{a}}\right)$, apparent clearance $(\mathrm{CL} / \mathrm{F})$, central compartment volume $(\mathrm{Vc} / \mathrm{F})$, intercompartmental clearance $(\mathrm{Q} / \mathrm{F})$, and peripheral compartment volume $(\mathrm{Vp} / \mathrm{F})$.

\section{PK-PD Model}

A PK-PD model was also developed to characterize the serum calcium response to daily teriparatide injection as a function of time and teriparatide concentration. The PK-PD analysis data set contained 3,085 calcium and 1,282 teriparatide concentrations obtained from 360 patients whose age and weight ranged from 49 to 85 years (10th-90th percentile range 60-77 years) and 39.5 to $120 \mathrm{~kg}$ (10th90th percentile range $51-80 \mathrm{~kg}$ ) at study entry, respectively. Baseline serum calcium values ranged from 8.28 to $10.6 \mathrm{mg} / \mathrm{dl}$, mean value of 9.2 with a variability of $0.38 \mathrm{mg} /$ $\mathrm{dl}$ ( \pm standard deviation [SD]). An indirect-response model was developed using the following equation:

$\frac{\mathrm{dCalcium}}{\mathrm{d} t}=K_{\mathrm{in}} \cdot\left[1+\frac{E_{\mathrm{max}} \cdot C_{\mathrm{TPTD}}}{E C_{50}+C_{\mathrm{TPTD}}}\right]-K_{\mathrm{out}} \cdot C_{\text {Calcium }}$

where $K_{\text {in }}$ represents the zero-order production rate for change in serum calcium over time; $K_{\text {out }}$ is the first-order dissipation rate for calcium response; $C_{\text {Calcium }}$ and $C_{\mathrm{TPTD}}$ represent the calcium and teriparatide concentrations, respectively; $E_{\max }$ is the maximum calcemic response; and $\mathrm{EC}_{50}$ is the teriparatide concentration required to produce $50 \%$ of the maximum calcium effect.

\section{Data Analysis Procedure}

A sequential PK-PD analysis was performed, with the final parameter values from the population PK model being fixed during the PK-PD analysis. The PK and PK-PD models were developed using nonlinear mixed-effects modeling techniques in NONMEM (version VI) with PREDPP [11]. First-order conditional estimation with interaction (NONMEM User's Guide, Part VII) was used for the PK model, while first-order estimation was used for the PK-PD model. Additive and proportional interpatient variability models were tested. Three residual error models-(1) additive, (2) proportional, and (3) combined additive and proportionalwere also evaluated.

Model development strategies were consistent between the PK and full PK-PD analyses. First, basic structural models were built, with interpatient variability included on all parameters where it was estimable. In addition, covariance between parameters was tested using the OMEGA BLOCK option in NONMEM. Second, factors potentially influencing the PK and PD of teriparatide, including age, body weight, injection site, creatinine clearance, smoking, and alcohol history, were examined graphically and then tested through estimation of covariate models.

A stepwise forward and backward approach was applied such that each covariate was added or deleted one at a time. When possible, physiologic relevance was considered in covariate selection. However, the log-likelihood ratio test was the primary criterion used to determine the appropriateness of a selected covariate. A decrease in the objective function value of $\geq 6.635(P<0.01$, degree of freedom $=1)$ 
in a full model compared with the reduced model indicated that the full model was the superior model. If the difference in the objective function value was $<6.635$, then it was assumed that there was no significant difference between the two models and the simpler reduced model (i.e., without covariate) was retained.

Potentially significant covariates were then added to the base model in combination so that a full model containing all possible covariates was established. Highly correlated patient factors (e.g., age and years postmenopausal) were evaluated separately and the most statistically significant covariate was retained. The process was then reversed, with potential covariates being removed individually from the full model. Finally, covariates retained in the final model were those which resulted in a significant increase in objective function ( $\geq 10.828$ points for 1 degree of freedom, $P<0.001$ ), when removed from the full model. The fit of the resulting model was evaluated using diagnostic plots of predicted versus observed values, as well as a visual predictive check [12].

Predose serum calcium was also analyzed by analysis of covariance (ANCOVA), with baseline as a covariate using SAS v.8.2 for MVS (SAS Institute, Cary, NC). The numbers of patients with calcium values $>10.6$ or $>11.0 \mathrm{mg} / \mathrm{dl}$ were compared between treatment groups using Fisher's exact test.

\section{Results}

The treatment groups were well balanced for baseline characteristics and disease severity [6]. Previous osteoporosis drug use was reported by 14.9 and $15.5 \%$ of patients in the placebo and teriparatide $20 \mu \mathrm{g}$ groups, respectively. The mean $( \pm \mathrm{SD})$ duration of teriparatide treatment during the study was $18 \pm 5$ months in the placebo and $18 \pm 6$ months in the teriparatide $20 \mu \mathrm{g}$ groups.

\section{Teriparatide PK}

The teriparatide concentration-time profile is characterized by rapid absorption and elimination with an obvious monoexponential decline in concentrations. The peptide reached a maximum concentration about $30 \mathrm{~min}$ after subcutaneous injection and then declined with a half-life of $1 \mathrm{~h}$. This half-life reflects the time required for absorption from the injection site as the true elimination half-life following intravenous administration was $5 \mathrm{~min}$ [13].

In most subjects, teriparatide concentrations were $<50 \mathrm{pg} / \mathrm{ml}$ by $3 \mathrm{~h}$ after injection of a $20-\mu \mathrm{g}$ dose. By extrapolating the teriparatide concentration-time profile to infinite time, we estimated the duration of exposure above the upper limit of normal for endogenous PTH $(65 \mathrm{pg} / \mathrm{ml})$ and above basal concentrations ( $28 \mathrm{pg} / \mathrm{ml})$. On a molar basis, the teriparatide concentrations briefly exceeded the upper limit of normal for about $3 \mathrm{~h}$ and remained above basal concentrations for about $4 \mathrm{~h}$.

A one-compartment absorption rate-limited PK model with first-order elimination and interpatient variability on $\mathrm{CL} / \mathrm{F}, \mathrm{V} / \mathrm{F}$, and $K_{\mathrm{a}}$ served as the base model for further covariate search and model refinement; a two-compartment model did not significantly improve the fit of the data. Of all the covariates tested, only body weight and injection site were found to have small but statistically significant influences on the rate of teriparatide absorption. No association was found between age, smoking, alcohol history, or renal function and teriparatide PK. Injections into the thigh were estimated to have a $21 \%$ slower rate of absorption than abdominal wall injections, resulting in an $18 \%$ reduction in maximum teriparatide concentrations $\left(C_{\max }\right)$ and $1.5 \mathrm{~min}$ prolongation in the time to reach the peak concentration $\left(T_{\max }\right)$. Similarly, the rate of absorption was slower in heavier patients, resulting in a $26 \%$ reduction in $C_{\max }$ and a 2.3 min prolongation in $T_{\max }$, when comparing the 10th and 90th percentiles of weight values in the analysis data set. The slower rates of absorption did not affect the overall systemic exposure to teriparatide. Furthermore, population PD analyses demonstrated no statistically significant differences in lumbar spine BMD or biochemical marker responses based on body weight or injection site (data not shown). Therefore, the magnitude of the effects of body weight and injection site on the rate of teriparatide absorption, and the resultant peak serum concentrations, is not considered to be clinically meaningful.

The $K_{\mathrm{a}}$ of $0.63 \mathrm{~h}^{-1}$ supports the assertion of absorption rate-limited PK since the half-life based upon this rate constant (i.e., $\ln 2 / 0.63 \mathrm{~h}^{-1}=1.1 \mathrm{~h}$ ) is consistent with the observed half-life of teriparatide following subcutaneous injection. Interpatient variability, expressed as percent coefficient of variation (CV), was $30 \%$. Teriparatide CL/F (approximately 62 1/h, 46\% CV) exceeded the rate of normal liver plasma flow, consistent with the known hepatic and extrahepatic mechanisms of PTH metabolism and clearance [3, 14-16]. The V/F following subcutaneous administration was approximately $7.81(107 \% \mathrm{CV})$. The proportional and additive residual error terms were estimated to be $40 \%$ and $16 \mathrm{pg} / \mathrm{ml}$ (SD), respectively. The PK parameters were estimated with good precision, with standard errors of estimation $(\% \mathrm{SEE}) \leq 10 \%$ for the primary PK parameters $\left(\mathrm{K}_{\mathrm{a}}, \mathrm{CL} /\right.$ $\mathrm{F}$, and $\mathrm{V} / \mathrm{F}$ ) and $\% \mathrm{SEE} \leq 25 \%$ for all other fixed and random effect parameters in the model.

\section{Calcium PD}

The uncorrected serum calcium concentration vs. time profiles are shown for teriparatide $20 \mu \mathrm{g}$-treated patients 

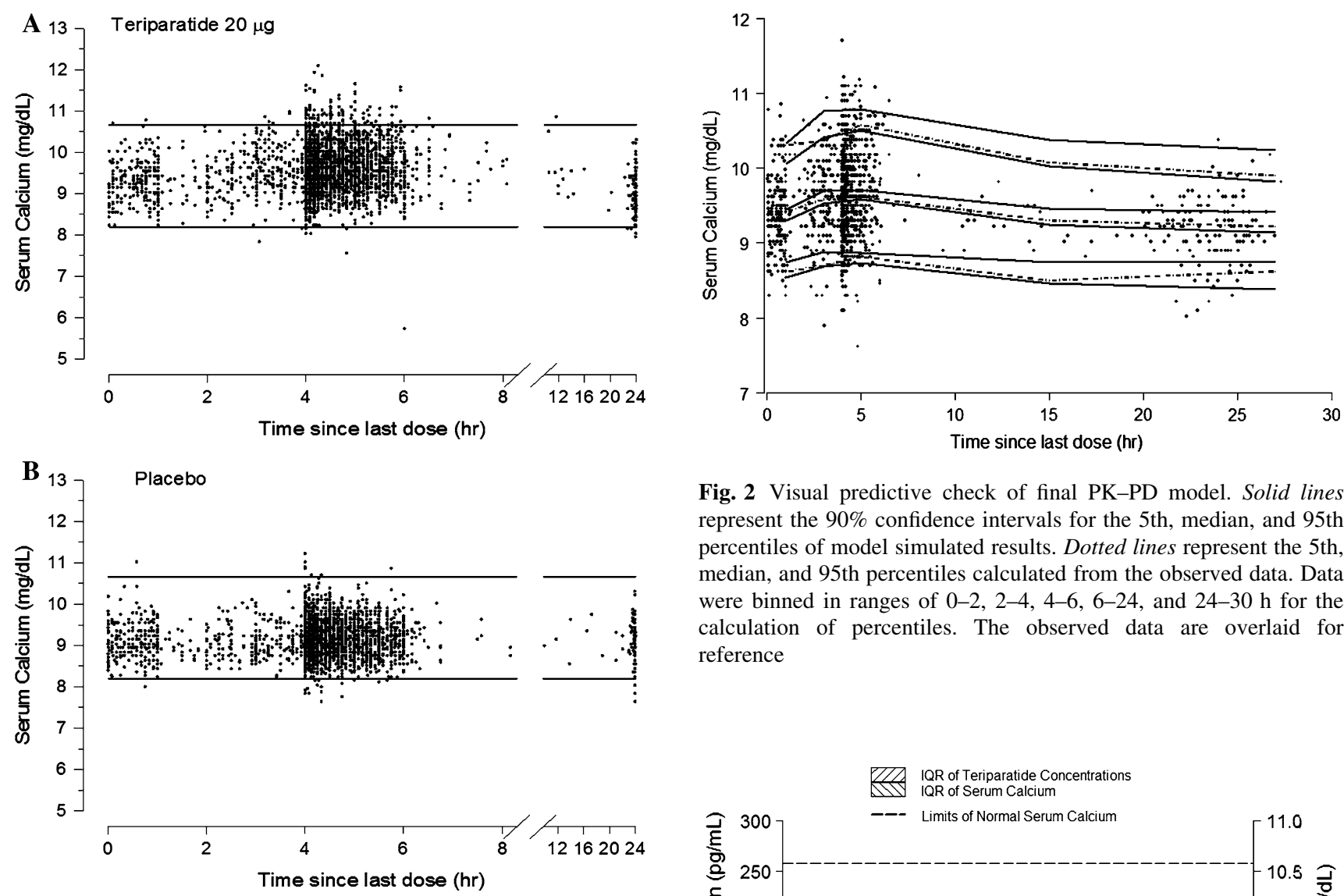

Fig. 2 Visual predictive check of final PK-PD model. Solid lines represent the $90 \%$ confidence intervals for the 5th, median, and 95th percentiles of model simulated results. Dotted lines represent the 5th, median, and 95 th percentiles calculated from the observed data. Data were binned in ranges of $0-2,2-4,4-6,6-24$, and $24-30 \mathrm{~h}$ for the calculation of percentiles. The observed data are overlaid for reference

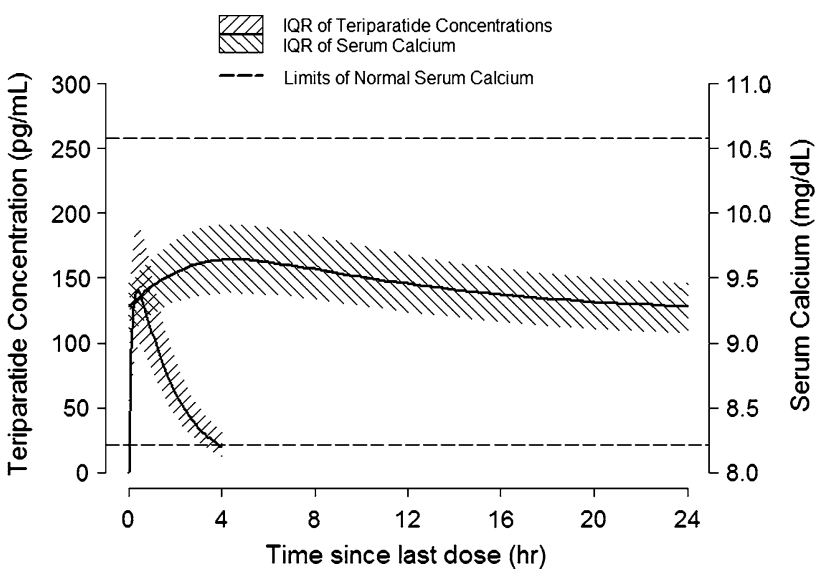

Fig. 1 Serum calcium concentrations vs. time since last teriparatide $20 \mu \mathrm{g}$ (a) or placebo (b) dose. The upper $(10.6 \mathrm{mg} / \mathrm{dl}, 2.64 \mathrm{mmol} / \mathrm{l})$ and lower $(8.2 \mathrm{mg} / \mathrm{dl})$ limits of normal for serum calcium are shown by the horizontal lines

(Fig. 1a) and placebo-treated patients (Fig. 1b). The normal range for uncorrected serum calcium is $8.2-10.6 \mathrm{mg} / \mathrm{dl}$. A placebo-response model was not developed because calcium levels were not increased after oral calcium administration.

The baseline serum calcium level was estimated from the PK-PD model to be $9.2 \mathrm{mg} / \mathrm{dl}(2.3 \mathrm{mmol} / \mathrm{l}, 3.0 \% \mathrm{CV})$. The PD parameter estimates that characterized the relationship between teriparatide concentration and calcemic response were $K_{\text {in }}=1.1 \mathrm{mg} /(\mathrm{dl} \cdot$ hour $), K_{\text {out }}=0.12 \mathrm{~h}^{-1}$, $E_{\max }=19.5 \%(62 \% \mathrm{CV})$, and $\mathrm{EC}_{50}=54 \mathrm{pg} / \mathrm{ml}$. The residual error was estimated to be $4.0 \%$. The $\%$ SEE for the PD parameters was $\leq 35 \%$. None of the covariates tested, including age, body weight, smoking, alcohol history, and injection site, had a statistically significant effect on calcemic response to teriparatide. The visual predictive check for the final PK-PD model is shown in Figure 2. The relationship between serum teriparatide concentrations and the resulting calcemic response based on the PK-PD model is illustrated in Figure 3.

Following daily injections of teriparatide $20 \mu \mathrm{g}$, the serum calcium concentration increased transiently, beginning approximately $2 \mathrm{~h}$ after dosing and reaching a

Fig. 3 Model predicted teriparatide concentration-time profile and the resulting serum calcium response following teriparatide $20 \mu \mathrm{g}$ injection. Upper $(10.6 \mathrm{mg} / \mathrm{dl}, 2.64 \mathrm{mmol} / \mathrm{l})$ and lower $(8.2 \mathrm{mg} / \mathrm{dl})$ limits of normal for serum calcium are shown by the horizontal lines. $I Q R$ interquartile range

maximum concentration at $4.25 \mathrm{~h}$ (median increase, $0.4 \mathrm{mg} / \mathrm{dl}[0.1 \mathrm{mmol} / \mathrm{l}])$. Fifty patients $(9.4 \%)$ in the teriparatide $20 \mu \mathrm{g}$ group had serum calcium levels above the upper limit of normal 4-6 h after dosing compared with six cases $(1.1 \%)$ in the placebo group $(P<0.001)$. The serum calcium concentration began to decline approximately $6 \mathrm{~h}$ after dosing and returned to predose levels by $16-24 \mathrm{~h}$ after each dose. Because the calcium concentrations returned to predose values prior to administration of the next dose, there was neither a sustained elevation in the calcemic response nor accumulation over time. 


\section{Predose Serum Calcium}

Approximately $25 \%$ of the serum calcium samples collected at months 1,6 , and 12 and $8 \%$ of the samples at months 3 , 18 , and 24 were obtained in the 16 - to 24 -h postdose interval and formed the basis for the predose serum calcium analysis. Mean ( \pm standard error [SE]) predose serum calcium values at baseline, $1,3,6,12,18$, and 24 months were $9.20 \pm$ $0.02,9.19 \pm 0.03,9.12 \pm 0.08,9.29 \pm 0.03,9.40 \pm 0.03$, $9.30 \pm 0.08$, and $9.26 \pm 0.05 \mathrm{mg} / \mathrm{dl}$, respectively, for the teriparatide $20 \mu \mathrm{g}$-treated patients and $9.22 \pm 0.02,9.09 \pm$ $0.03,8.93 \pm 0.09,9.09 \pm 0.03,9.27 \pm 0.03,9.31 \pm 0.08$, and $9.18 \pm 0.05 \mathrm{mg} / \mathrm{dl}$, respectively, for the placebo-treated patients. Baseline serum calcium did not differ between treatment groups. Predose serum calcium was significantly $(P<0.05)$ higher than baseline at 6 and 12 months $(+0.09$ and $+0.2 \mathrm{mg} / \mathrm{dl}$, respectively) for teriparatide-treated patients. In contrast, for placebo-treated patients, the predose serum calcium values were significantly $(P<0.05)$ lower than baseline at 1 and 6 months $(-0.13$ and $-0.13 \mathrm{mg} / \mathrm{dl}$, respectively) and significantly $(P<0.05)$ higher than baseline at 12 months $(+0.05 \mathrm{mg} / \mathrm{dl})$. There were no statistically significant treatment differences in the incidence of elevated serum calcium above the normal range. One teriparatide $20 \mu$ g-treated patient $(0.4 \%, 1 / 223)$ had a predose serum calcium value $>10.6 \mathrm{mg} / \mathrm{dl}$ and no teriparatide $20 \mu \mathrm{g}$-treated patient had a predose serum calcium $>11.0 \mathrm{mg} / \mathrm{dl}$. In the placebo group, one patient $(0.4 \%$, $1 / 237$ ) had a predose serum calcium value $>10.6 \mathrm{mg} / \mathrm{dl}$ and one patient $(0.4 \%, 1 / 237)$ had a predose serum calcium value $>11.0 \mathrm{mg} / \mathrm{dl}$.

To determine whether the transient increases in postdose serum calcium values were associated with any clinical adverse effects commonly associated with hypercalcemia, adverse events in patients in the teriparatide group who had elevated $(>10.6 \mathrm{mg} / \mathrm{dl}$ or $2.647 \mathrm{mmol} / \mathrm{l})$ postdose serum calcium are summarized in comparison with the overall cohort of patients receiving teriparatide $20 \mu \mathrm{g} / \mathrm{day}$ (Table 1). Except for a case of acute pancreatitis $(n=1)$, there were no specific outstanding safety findings observed in those patients who had hypercalcemia during the course of the trial. The analysis was limited because of the low number of cases.

\section{Discussion}

Our results demonstrate that the duration of calcemic response after the subcutaneous injection of teriparatide $20 \mu \mathrm{g}$ is brief. One reason for this is the rapid rates of absorption and elimination of teriparatide. After subcutaneous injection, maximum teriparatide concentrations are achieved within $30 \mathrm{~min}$, followed by a rapid decline from
Table 1 Adverse events commonly associated with hypercalcemia summarized in patients treated with teriparatide $20 \mu \mathrm{g} /$ day who had elevated ( $>10.6 \mathrm{mg} / \mathrm{dl}) 4-6 \mathrm{~h}$ postdose serum calcium in comparison with the overall cohort of patients in the teriparatide group

\begin{tabular}{lrl}
\hline & $\begin{array}{l}\text { Overall cohort } \\
(n=541)\end{array}$ & $\begin{array}{l}\text { Patients }{ }^{\mathrm{a}} \text { with serum } \\
\mathrm{Ca}>10.6(n=50)\end{array}$ \\
\hline $\begin{array}{l}\text { Neurological } \\
\text { Headache }\end{array}$ & $44(8.1 \%)$ & $4(8.0 \%)$ \\
$\begin{array}{l}\text { Depression } \\
\text { Gastrointestinal }\end{array}$ & $21(3.9 \%)$ & $3(6.0 \%)$ \\
Abdominal pain & $48(8.9 \%)$ & $6(12.0 \%)$ \\
Pancreatitis & $1(0.2 \%)$ & $1(2.0 \%)$ \\
Nausea & $51(9.4 \%)$ & $6(12.0 \%)$ \\
Anorexia & $8(1.5 \%)$ & $1(2.0 \%)$ \\
Constipation & $32(5.9 \%)$ & $6(12.0 \%)$ \\
Vomiting & $19(3.5 \%)$ & $3(6.0 \%)$ \\
Peptic ulcer/gastritis & $8(1.5 \%)$ & $2(4.0 \%)$ \\
Cardiovascular & & $1(2.0 \%)$ \\
Arrhythmias & $9(1.7 \%)$ & $4(8.0 \%)$ \\
Hypertension & $41(7.6 \%)$ & \\
\hline
\end{tabular}

a $n(\%)$

the systemic circulation with a half-life of $1 \mathrm{~h}$. Teriparatide transiently increases serum calcium, with the maximal effect observed at approximately $4.25 \mathrm{~h}$ (median increase, $0.4 \mathrm{mg} / \mathrm{dl}$ or $0.1 \mathrm{mM}$ ) followed by a decline to predose levels before the next teriparatide dose is administered $24 \mathrm{~h}$ later.

The results of studies in rats have also shown that the therapeutic interval for $\mathrm{PTH}(1-34)$ exposure is brief but that prolonged exposure results in severe hypercalcemia. Using a total daily dose of $80 \mu \mathrm{g} / \mathrm{kg}$ body weight of hPTH(1-34), Dobnig and Turner [17] demonstrated that a single subcutaneous injection or continuous infusion for 1 or $2 \mathrm{~h}$ /day had no effect on serum calcium. In contrast, continuous infusion of hPTH(1-34) for $6 \mathrm{~h}$ /day resulted in hypercalcemia. Frolik et al. [18] confirmed that sustained elevated serum calcium concentrations occurred following subcutaneous injections of teriparatide every hour for six injections but not following once-daily subcutaneous injection of teriparatide or six injections within $1 \mathrm{~h}$.

The PK-PD profile of teriparatide $20 \mu \mathrm{g}$ has practical clinical implications because the PK and calcium PD results show notable differences compared to those of the full human recombinant PTH (rhPTH[1-84]), which is also available for the treatment of osteoporosis in some countries at a daily dose of $100 \mu \mathrm{g}$.

The PK and PD of single-dose rhPTH(1-84) subcutaneous injection (dose range $0.02-5.0 \mu \mathrm{g} / \mathrm{kg}$ ) were reported by Schwietert et al. [19]. The serum concentration-time profile of rhPTH(1-84) exhibited a double-peak profile, with the first peak appearing approximately 5-10 min after 
dosing and the second peak occurring about $1.5-2 \mathrm{~h}$ after subcutaneous injection of this hormone [19]. Interestingly, at all $\mathrm{rhPTH}(1-84)$ doses administered, there was a fixed equilibrium between elevated $\mathrm{PTH}(1-84)$ and $\mathrm{PTH}(1-34)$, a biologically active fragment of $\mathrm{PTH}(1-84)$ that was further accompanied by a double-peak profile in serum total calcium concentrations [19]. The apparent terminal half-life of rhPTH(1-84) was reported to be $1.5-2.5 \mathrm{~h} \mathrm{[19}$, $20]$. In contrast, the time to peak concentration of teriparatide is $30 \mathrm{~min}$ following injection, with a half-life of $1 \mathrm{~h}$ [13].

Based on the PK concentration-time profile for each drug, we calculated the duration of time that PTH concentrations were $>65 \mathrm{pg} / \mathrm{ml}$, the upper limit of normal for endogenous PTH, and $>28 \mathrm{pg} / \mathrm{ml}$, the typical basal endogenous PTH concentration for postmenopausal women. Using the published PK profile [19] for $\operatorname{rhPTH}(1-84)$, we calculated that the time above the upper limit exceeded $6 \mathrm{~h}$ and the time above basal concentrations exceeded $9 \mathrm{~h}$ for the marketed dose of $100 \mu \mathrm{g}(1.66 \mu \mathrm{g} / \mathrm{kg}$, assuming an average body weight of $60 \mathrm{~kg}$ ). In contrast, teriparatide concentrations exceeded the upper limit of normal and remained above the basal concentrations for approximately 3 and $4 \mathrm{~h}$, respectively. Such differences compared to the PK-PD relationship of teriparatide could translate into the formation of a longer "drug exposure time" for rhPTH(1-84) compared with teriparatide. Indeed, the resulting calcemic response elicited by $100 \mu \mathrm{g} \operatorname{rhTH}(1-84)$ led to a peak serum calcium increase of $0.6 \mathrm{mg} / \mathrm{dl}(0.15 \mathrm{mmol} / \mathrm{l})$ between 6 and $8 \mathrm{~h}$ postdose [20]. These apparent differences in the duration of exposure may help to explain why hypercalcemia and hypercalciuria are relatively rare events following administration of teriparatide $20 \mu \mathrm{g}[6,21,22]$, although they have been more frequently reported in the rhPTH(1-84) $100 \mu \mathrm{g}$ pivotal trial [23]. Whether it is the slower rate of absorption and elimination of $\operatorname{rhPTH}(1-84)$ due to its larger size and/or the parallel generation of PTH(1-34) and possibly other biologically active aminoterminal PTH fragments whose biological half-lives are less well characterized that leads to a larger calcemic response than teriparatide has yet to be determined.

Another potential explanation for the differences in the calcemic responses is that the dose of $\operatorname{rhPTH}(1-84)$ used in the pivotal phase 3 trial ( $100 \mu \mathrm{g} / \mathrm{day}, 10.62 \mu \mathrm{mol} /$ day $)$ [23] is approximately twofold greater on a molar basis than teriparatide $20 \mu \mathrm{g}$. However, it has been reported that the bioavailability of rhPTH(1-84) is 55\% [24] compared with the $95 \%$ bioavailability of teriparatide [25]. Thus, when adjusting for molecular weight and bioavailability, the relative doses administered in the $\operatorname{rhPTH}(1-84)$ pivotal phase 3 trial [23] and the teriparatide Fracture Prevention Trial [6] were 5.84 and $4.61 \mu \mathrm{mol}$, respectively, a difference that is unlikely to explain the disparity in the rates of hypercalcemia or drug exposure time between the two studies.

In conclusion, the pharmacologic effect of teriparatide following once-daily subcutaneous administration produces a modest but transient increase in serum calcium, consistent with the known effects of endogenous PTH on mineral metabolism. The PK-PD indirect-response model illustrates that the excursion in serum calcium is brief due to the short length of time that teriparatide concentrations are elevated.

Acknowledgments This study was funded by Lilly Research Laboratories, Eli Lilly and Company, Indianapolis, IN. Editorial assistance was provided by Gail P. Dalsky, PhD, an employee of Eli Lilly and Company.

Open Access This article is distributed under the terms of the Creative Commons Attribution Noncommercial License which permits any noncommercial use, distribution, and reproduction in any medium, provided the original author(s) and source are credited.

\section{References}

1. Brown EM (1991) Extracellular $\mathrm{Ca}^{2+}$ sensing, regulation of parathyroid cell function, and role of $\mathrm{Ca}^{2+}$ and other ions as extracellular (first) messengers. Physiol Rev 71:371-411

2. Lewin E, Nielsen PK, Olgaard K (1995) The calcium/parathyroid hormone concept of the parathyroid glands. Curr Opin Nephrol Hypertens 4:324-333

3. Habener JF, Rosenblatt M, Potts JT Jr (1984) Parathyroid hormone: biochemical aspects of biosynthesis, secretion, action, and metabolism. Physiol Rev 64:985-1053

4. Kronenberg HM, Bringhurst FR, Segre GV, Potts JT Jr (2001) Parathyroid hormone biosynthesis and metabolism. In: Bilezikian JP, Marcus R, Levine MA (eds) The parathyroids: basic clinical concepts, 2nd edn. Academic Press, San Diego, pp 17-30

5. McClung MR, San Martin J, Miller PD, Civitelli R, Bandeira F, Omizo M, Donley DW, Dalsky GP, Eriksen EF (2005) Opposite bone remodeling effects of teriparatide and alendronate in increasing bone mass. Arch Intern Med 165:1762-1768

6. Neer RM, Arnaud CD, Zanchetta JR, Prince R, Gaich GA, Reginster JY, Hodsman AB, Eriksen EF, Ish-Shalom S, Genant HK, Wang O, Mitlak BH (2001) Effect of parathyroid hormone (1-34) on fractures and bone mineral density in postmenopausal women with osteoporosis. N Engl J Med 344:1434-1441

7. Saag KG, Shane E, Boonen S, Marin F, Donley DW, Taylor KA, Dalsky GP, Marcus R (2007) Teriparatide or alendronate in glucocorticoid-induced osteoporosis. N Engl J Med 357: 2028-2039

8. Goltzman D (2008) Studies on the mechanisms of the skeletal anabolic action of endogenous and exogenous parathyroid hormone. Arch Biochem Biophys 473:218-224. doi:10.1016/j.abb. 2008.03.003

9. Ludden TM (1988) Population pharmacokinetics. J Clin Pharmacol 28:1059-1063

10. Sheiner LB, Steimer JL (2000) Pharmacokinetic/pharmacodynamic modeling in drug development. Annu Rev Pharmacol Toxicol 40:67-95. doi:10.1146/annurev.pharmtox.40.1.67

11. Beal SL, Sheiner LB, Boeckmann AJ (eds) (2006) NONMEM users guides (1989-2006). Icon Development Solutions, Ellicott City, MD 
12. Yano Y, Beal SL, Sheiner LB (2001) Evaluating pharmacokinetic/ pharmacodynamic models using the posterior predictive check. J Pharmacokinet Pharmacodyn 28:171-192. doi:10.1023/A:101 1555016423

13. Eli Lilly and Company (2009) Teriparatide [rhPTH(1-34)] (Forteo) United States package insert

14. Martin KJ, Hruska KA, Freitag JJ, Klahr S, Slatopolsky E (1979) The peripheral metabolism of parathyroid hormone. N Engl J Med 301:1092-1098

15. Goltzman D, Bennett HP, Koutsilieris M, Mitchell J, Rabbani SA, Rouleau MF (1986) Studies of the multiple molecular forms of bioactive parathyroid hormone and parathyroid hormone-like substances. Recent Prog Horm Res 42:665-703

16. Daugaard H (1996) Peripheral metabolism of parathyroid hormone. Studies with isolated perfused kidneys and livers from normal and uremic rats. Dan Med Bull 43:203-215

17. Dobnig H, Turner RT (1997) The effects of programmed administration of human parathyroid hormone fragment (1-34) on bone histomorphometry and serum chemistry in rats. Endocrinology 138:4607-4612

18. Frolik CA, Black EC, Cain RL, Satterwhite JH, Brown-Augsburger PL, Sato M, Hock JM (2003) Anabolic and catabolic bone effects of human parathyroid hormone (1-34) are predicted by duration of hormone exposure. Bone 33:372-379. doi:10.1016/ S8756-3282(03)00202-3

19. Schwietert HR, Groen EW, Sollie FA, Jonkman JH (1997) Single-dose subcutaneous administration of recombinant human parathyroid hormone $[\mathrm{rhPTH}(1-84)]$ in healthy postmenopausal volunteers. Clin Pharmacol Ther 61:360-376

20. $\mathrm{rhPTH}(1-84)$ (Preotact) Summary of product characteristics (2007), http://www.emea.europa.eu/humandocs/PDFs/EPAR/pre otact/H-659-PI-en.pdf. Accessed 30 Sep 2008

21. Miller PD, Bilezikian JP, Diaz-Curiel M, Chen P, Marin F, Krege JH, Wong M, Marcus R (2007) Occurrence of hypercalciuria in patients with osteoporosis treated with teriparatide. J Clin Endocrinol Metab 92:3535-3541. doi:10.1210/jc.2006-2439

22. Obermayer-Pietsch BM, Marin F, McCloskey EV, Hadji P, Farrerons J, Boonen S, Audran M, Barker C, Anastasilakis AD, Fraser WD, Nickelsen T (2008) Effects of two years of daily teriparatide treatment on BMD in postmenopausal women with severe osteoporosis with and without prior antiresorptive treatment. J Bone Miner Res 23:1591-1600. doi:10.1359/jbmr.080506

23. Greenspan SL, Bone HG, Ettinger MP, Hanley DA, Lindsay R, Zanchetta JR, Blosch CM, Mathisen AL, Morris SA, Marriott TB (2007) Effect of recombinant human parathyroid hormone (1-84) on vertebral fracture and bone mineral density in postmenopausal women with osteoporosis: a randomized trial. Ann Intern Med 146:326-339

24. EPAR (2007) Preotact product information. http://www.emea. europa.eu/humandocs/Humans/EPAR/preotact/H-659-PI-en.pdf

25. EPAR (2009) Forsteo product information. http://www.emea.europa. eu/humandocs/PDFs/EPAR/forsteo/emea-combined-h425en.pdf 